\title{
JロURNALS
}
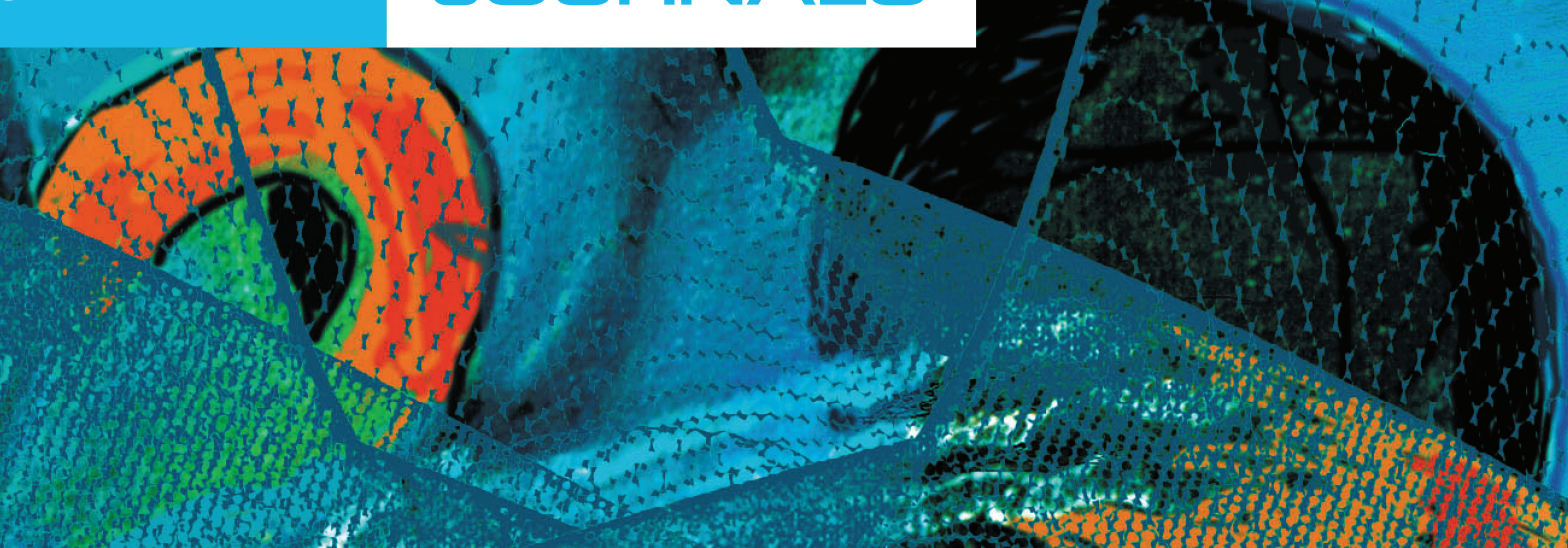

4.

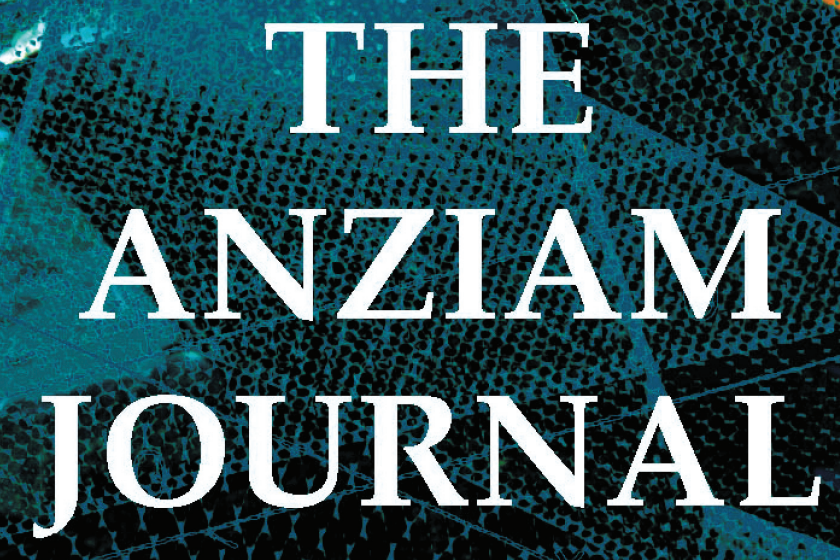

(The Australian \& New Zealand

Industrial and Applied

\section{Mathematics Joumal)}

Editors: Andrew Bassom E Graeme Hoching Volume 51 . Issue $3 \cdot$ Januaty 2010 


\section{Editorial Office and Addresses}

Editors in Chief: $\quad$ A. P. BASsOM (bassom@maths.uwa.edu.au)

School of Mathematics \& Statistics

University of Western Australia

Crawley WA 6009, Australia

G. C. Hocking (G.Hocking@murdoch.edu.au)

Department of Mathematics \& Statistics

Murdoch University

Murdoch WA 6150, Australia

Technical Editor: T. PopIEL (popiel@maths.uwa.edu.au)

School of Mathematics \& Statistics

University of Western Australia

Crawley WA 6009, Australia

\section{Associate Editors}

J. BorweIn, School of Mathematics \& Physical Sciences, University of Newcastle, NSW

P. BROADBRIDGE, School of Engineering \& Mathematical Sciences, La Trobe University, VIC

R. S. BURACHIK, School of Mathematics \& Statistics, University of South Australia, SA

D. L. Clements, School of Mathematical Sciences, University of Adelaide, SA

R. L. DEWAR, Department of Theoretical Physics, Australian National University, ACT

A. C. Eberhard, Department of Mathematics, Royal Melbourne Institute of Technology, VIC

L. K. Forbes, School of Mathematics \& Physics, University of Tasmania, TAS

M. Hegland, Mathematical Sciences Institute, Australian National University, ACT

V. JEYAKUMAR, School of Mathematics, University of New South Wales, NSW

K. LAndman, Department of Mathematics \& Statistics, University of Melbourne, VIC

S. W. MCCUE, School of Mathematical Sciences, Queensland University of Technology, QLD

R. MCKIBbIN, Institute of Information \& Mathematical Sciences, Massey University, NZ

M. I. NELSON, School of Mathematics \& Applied Statistics, University of Wollongong, NSW

M. PlanK, Department of Mathematics \& Statistics, University of Canterbury, NZ

D. RALPH, The Judge Institute of Management Studies, Cambridge University, UK

H. M. SRIVASTAVA, Department of Mathematics \& Statistics, University of Victoria, Canada

K. L. TEO, Department of Mathematics \& Statistics, Curtin University, WA

J.-M. VANDEN-BRoECK, Department of Mathematics, University College London, UK

G. C. WAKE, Institute of Information \& Mathematical Sciences, Massey University, NZ

G. J. WEIR, Applied Mathematics Centre, Industrial Research Ltd, Lower Hutt, NZ

S.-P. ZHU, School of Mathematics \& Applied Statistics, University of Wollongong, NSW

Cover design by HILARY BOOTH. 